\title{
A Novel Microstrip-to-Microstrip Vertical Via Transition in X-Band Multilayer Packages
}

\author{
M. X. Yu \\ School of Physical Electronics, University of Electronic Science and Technology of China, No. 4, Section 2, North Jianshe Road, \\ Chengdu 610054, China
}

Correspondence should be addressed to M.X. Yu; yumengxia@263.net

Received 1 December 2015; Revised 2 February 2016; Accepted 21 February 2016

Academic Editor: Diego Masotti

Copyright (C) 2016 M. X. Yu. This is an open access article distributed under the Creative Commons Attribution License, which permits unrestricted use, distribution, and reproduction in any medium, provided the original work is properly cited.

\begin{abstract}
This paper investigates a novel X-band microstrip-to-microstrip vertical via transition with matching pads loaded signal via. This design has been proposed for a multilayer substrate package. The matching pads, which are located in the center of the signal via on each ground layer, are adopted to further improve the impedance matching level and thus attain better signal transition performance. A physics-based equivalent circuit modeling approach has been employed for this research. The right angle MS-toMS via transition was also designed using this technique. The simulated $S$-parameters indicate that the match-pad design made a breakthrough in achieving an approximate $-15 \mathrm{~dB}$ wide-band return loss reduction. The measured $S$-parameter of MS-to-MS transition showed that return loss with the matching pads is better than that without the matching pads.
\end{abstract}

\section{Introduction}

System-in-package ( $\mathrm{SiP})$ technology, based on the concept of integrating all of a system's electronic components into a single package, is growing rapidly as a highly efficient solution to the increasing demand for cost-effective, compact, and reliable RF modules [1]. A multilayer package substrate is usually made of high temperature cofired ceramic (HTCC), low temperature cofired ceramic (LTCC), thick film, thin film, or organic packaging [2-4]. HTCC is regarded as the lowest cost ceramic technology, but it suffers from a significantly higher insertion loss. Meanwhile, LTCC is the mainstream technology for three-dimensional packaging [5]. However, LTCC's drawback is its poor thermal conductivity and its difficulty managing shrinkage control during the firing process [6]. In order to improve the performance of RF packaging while also reducing cost, minimizing dimensions, and simplifying the fabrication, the selective anodized aluminum substrate [7] and the multilayer printed circuit board (PCB) technology [8] has been adopted over the last few years.

No matter the type of system-in-package approach, interconnection, especially the vertical via transition between different layers, plays an essential role in impacting the performance of all the RF circuits. A good vertical via interconnection design will guarantee both the signal quality and electromagnetic shielding property in packages. The multilayer circuits in $\mathrm{SiP}$ use these vias to realize the signal connection between different layers or integrated circuit (IC) devices. However, when the electrical length of the via is not much smaller than the signal wavelength at high frequencies, the vertical via structure will show the electrical discontinuities, further causing strong radiation from the edges of power/ground planes [9-12]. The discontinuity effect will excite several unwanted modes that lead to strong coupling and serious property reduction of the signal transmission in the system.

In order to insure the signal transition between different layers, eliminating the via-plane coupling and preventing power-ground resonances, coax-vias, which were intentionally placed adjacent to the signal via, were employed to serve as the return current via [10-12]. They provided the return current paths between ground plane pairs; studies had found that the insertion loss of the signal could be improved by these ground vias. In the discussion of [13], six ground vias were placed near the signal via to eliminate the via-plane coupling, and a physics-based equivalent circuit modeling approach $[14,15]$ was introduced for the ancillary study. Those studies were based on the theoretical model at a low frequency band. In [16], four through-hole ground vias were 


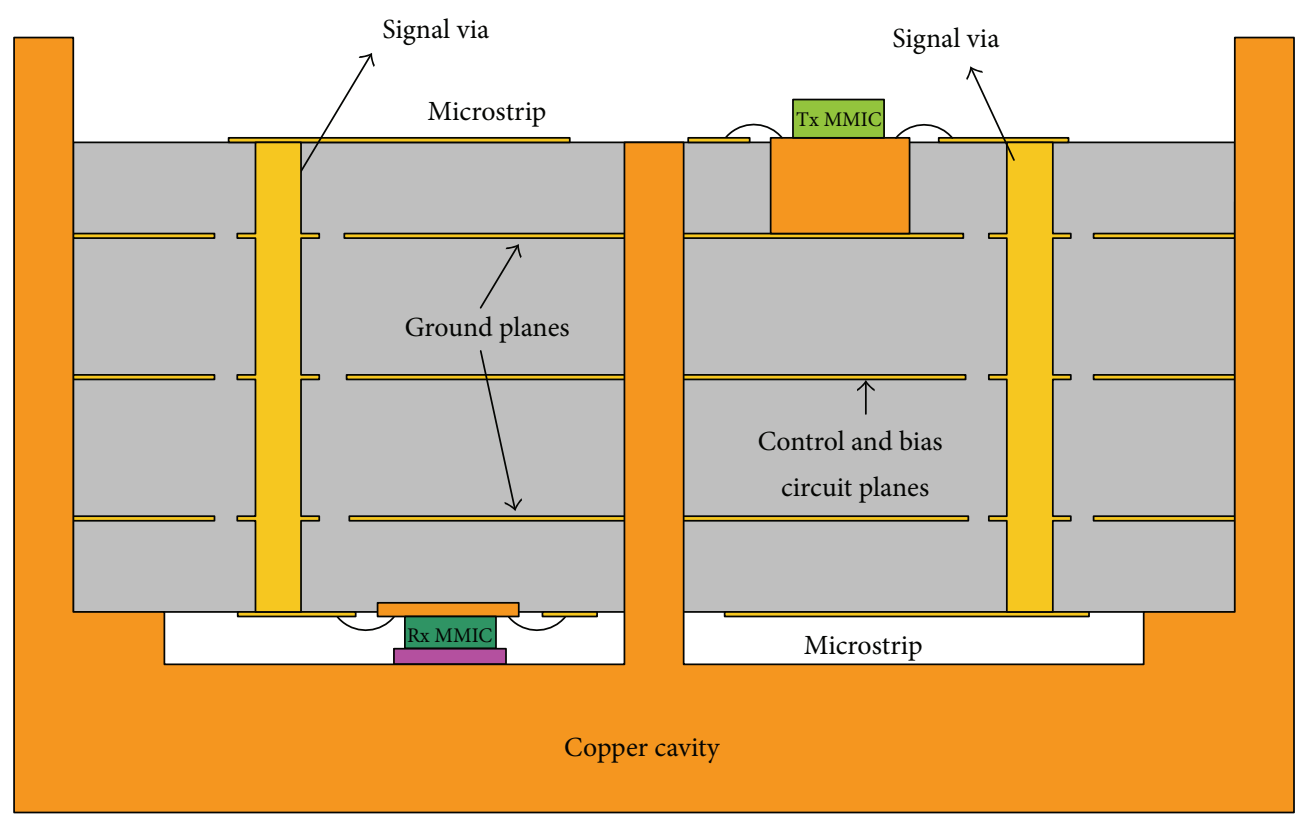

FIgURE 1: Side view of T/R module with vertical via transition.

mounted adjacent to the signal via to act as the coax-vias [17]; the structure was optimized; thus transition could achieve an insertion loss level under $1.8 \mathrm{~dB}$ and a return loss level above $15 \mathrm{~dB}$ up to $67 \mathrm{GHz}$. But in the extraction of an equivalent circuit, the employment of Ansoft Q3D was inapplicable. In other words, the coax-via structure will improve the impedance matching in multilayer circuits.

This paper introduces the new idea of using a matching pads loaded signal via structure to improve the performance of the signal transmission. This idea has been employed for the X-band microstrip-to-microstrip (MS-to-MS) multilayer substrate transition. Two rows of ground vias close to the signal via also support the return current paths in plane pairs. The focus of this design is to underline the contribution of the matching pads to develop the property of the signal transmission.

The simulation results shown in this paper have been divided into two blocks; the equivalent circuit of the transition structure was cautiously simulated using the method of moments (MoM), and the 3D configuration was verified using the finite-difference time-domain (FDTD) method.

\section{Design of a Vertical Via Transition}

2.1. The Application for $T / R$ Module. As shown in Figure 1 , a high-integration-density, low-cost system-in-package ( $\mathrm{SiP}$ ) T/R module structure has been demonstrated for employment on X-band phased array radar applications. The configuration of the multilayer substrate package involved the four layered composite medium substrates and highly integrated transmit-receive (T/R) MMICs mounted on the top surface of the first layer and the bottom side of the last layer; this was in addition to the matching pads loaded through-hole via which connected the microstrip lines on the top layer to the bottom layer. The pilot and biasing circuits were placed in the

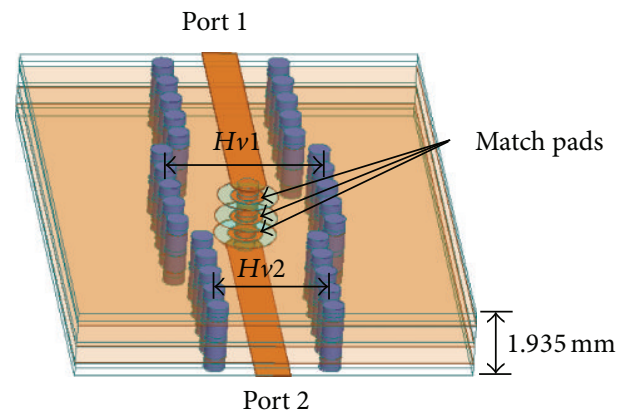

FIGURE 2: The 3D structure of the matching pads loaded MS-to-MS via transition.

middle layer of the package. The T/R module was realized by multilayer laminate technology, which has the advantages of low cost and high flexibility, while also being easy to fabricate.

The $3 \mathrm{D}$ view of the transition model is shown in Figure 2; the total height of the multilayer substrate is $1.935 \mathrm{~mm}$, which includes the first and last layers, $0.254 \mathrm{~mm}$ each, two middle layers of $0.508 \mathrm{~mm}$ each, and a prepreg of $0.12 \mathrm{~mm}$.

\subsection{Equivalent Circuit Model for Matching Pads Loaded Signal} Via Transition. For the multilayer circuit via transition, the extraction of each part of circuit impedance would be significant and a benefit for the $3 \mathrm{D}$ structure excogitation [18]. However, analysis of this electrical discontinuity is complicated in most cases [18-21]. On the one hand, changing the direction of the electromagnetic field caused by the vertical connection of the signal via would definitely excite a series of unsolicited TE modes (showing the effect of capacity) or TM modes (showing the inductive effect). On the other hand, because of the ground plane pairs and other additional conductors that would increase voltage routes and 
TABLE 1: Lumped parameters of physics-based equivalent circuits (units: $\mathrm{nH}$ for $L, \mathrm{pF}$ for $C$ ).

\begin{tabular}{lccccccrrr}
\hline$L 1$ & $L 2$ & $L 2 \_1$ & $L 3$ & $L 3 \_1$ & $L 4$ & $L 4 \_1$ & $L 5$ & $L 6$ \\
\hline 0.129 & 0.193 & 0.042 & 0.2347 & 0.043 & 0.2347 & 0.046 & 0.02347 & 0.116 \\
\hline$C 1$ & $C 2$ & $C 3$ & & $C 4$ & & \\
\hline 0.0816 & & & 0.0959 & 0.0797 & & 0.0923 & & \\
\hline
\end{tabular}

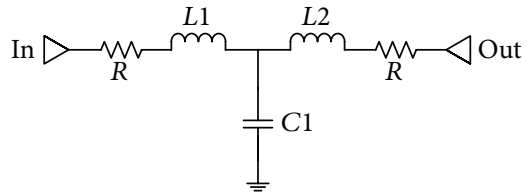

(a)

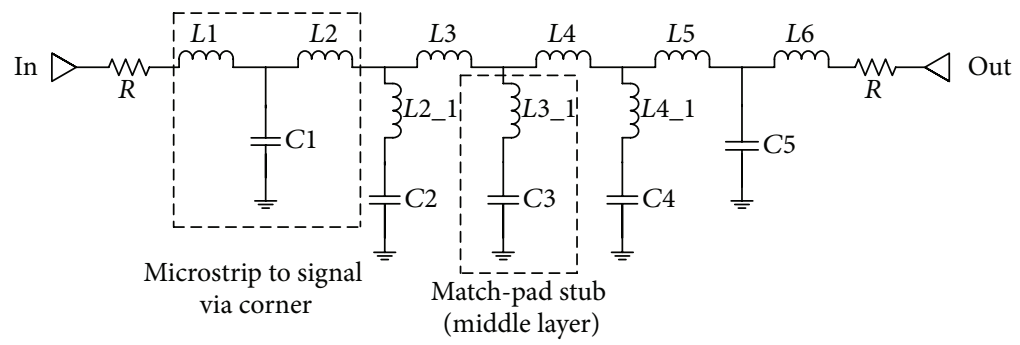

(b)

FIGURE 3: The physics-based equivalent circuit of the vertical via transition. (a) The T-type circuit for microstrip-to-vertical-signal-via corner; (b) the entire circuit for 3D transition structure.

return current paths, rendering the electrical discontinuity more irregular and causing more accidental changes, some phenomena are more difficult to investigate. It is hard to find an accurate formula or equivalent circuit to analyze the $3 \mathrm{D}$ via transition structure directly over a period of time.

The physics-based equivalent circuit modeling approach was used for this research. The $3 \mathrm{D}$ multilayer transition structure can be divided into subtle blocks corresponding to each part of an equivalent circuit. The benefit of this method is obvious in that each physical element of the circuit is directly linked to one or more layout features in geometry. This is conducive to the engineering design as well as the study. Figure 3 shows the divided equivalent model of the transition structure. The four-layer matching pads loaded signal via formation has been divided into five blocks in the direction of the signal transmission. The microstripto-vertical-signal-via corner along the surface of the top (or bottom) layer block is equivalent to a T-type circuit model, as shown in Figure 3(a). The matching pads for each ground plane are extracted into a series $L-C$ branch, which accounts for the effect displacement currents between the matching pads and the antipad, which is also shown in Figure 3(b). This is because the existence of coax-like vias results in capacitances too small to be equivalent included in the capacitance of microstrip-to-signal-via corner block; the multiport impedance matrix $Z_{\mathrm{pp}}$, which should be inserted into the plane pair block, is replaced by a length of inductance. The blocks are cascaded together to construct the entire equivalent circuit for a microstrip-to-microstrip transition.

All impedances of each block are calculated and simulated carefully using the method of moments. All impedances of each block are calculated and simulated carefully using the method of moments. Then, the values of $L$ and $C$ of the equivalent circuit are extracted according to the impedance of each block. The particular parameters of impedances are listed in
Table 1. The FDTD simulations and measurements in the next section have verified this physics-based equivalent circuit.

\subsection{The Design of Matching Pads Loaded Signal Via Transition.} For the effective transfer of RF signals, the impedance of the signal via should match the microstrip fed line with $50 \Omega$. Figure 4 shows the top view of the top circuit surface; two rows of ground vias (coax-like vias in Figure 4(a)) adjacent to the signal via have been employed to constitute the coax-like section. The denser coax-like vias not only have the function of impedance matching, but also better EMI performance. These vias also provide the return current path, which is the initial point in the signal transfer for high frequencies in Figure 5 to avoid coupling, and strong resonance between the plane pairs. Without the aforementioned vias, the return current will spread in plane pairs in the form of a displacement current.

Incidentally, as shown in Figure 6, two lines of shielding vias have been mounted near the sides of the microstrip to act as the simi-CBCPW (conductor backed coplanar waveguide) structure. This not only results in better dispersion properties and the lower EMI in RF transfers, but in higher power capabilities and preferable mechanical strength. This is suitable for the multilayer package application.

When the step has been completed, the distance between the two rows of coax-like vias has been confirmed, and the return current path is unchangeable. The matching pads are then adopted in the center of each ground layer to further improve the match level and to achieve a lower insertion loss. As shown in Figure 5, three matching pads are placed in the center of the signal via of each ground plane; it is then ready to be fabricated, which only requires etching the designed ring (realizing the matching pads and antipad at the same time) on the ground layer and then punching the through-hole on the center of the matching pads. The idea of this design is to add 


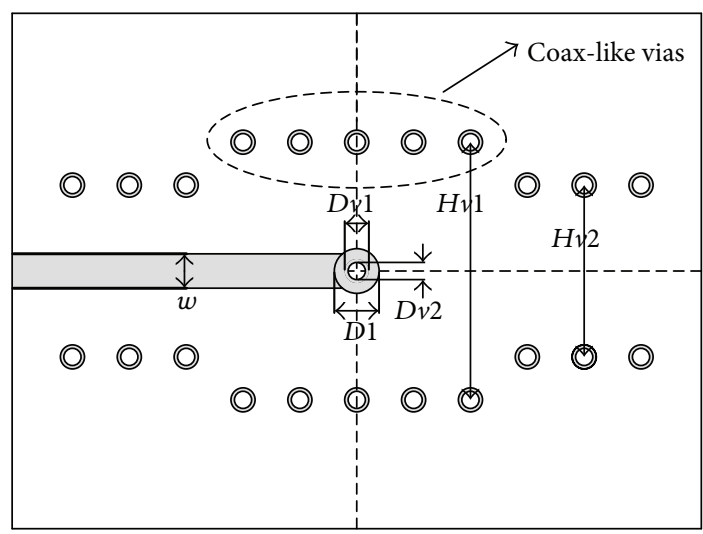

(a)

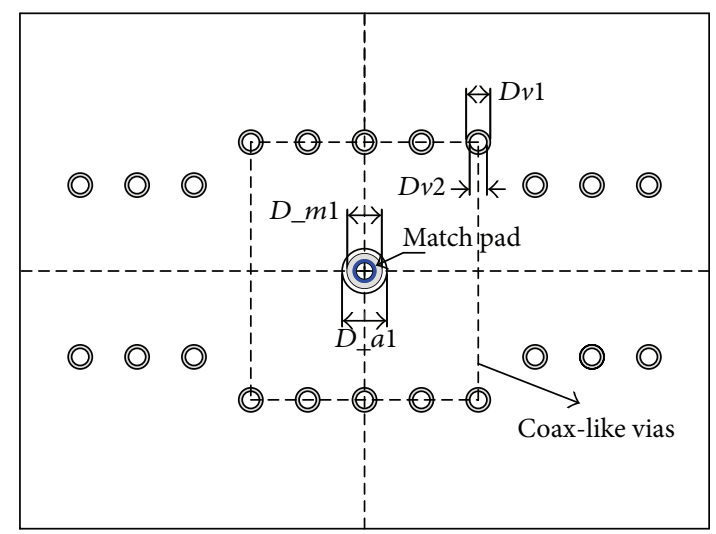

(b)

Figure 4: Top view of matching pads loaded transition. (a) The first layer; (b) the first ground plane.

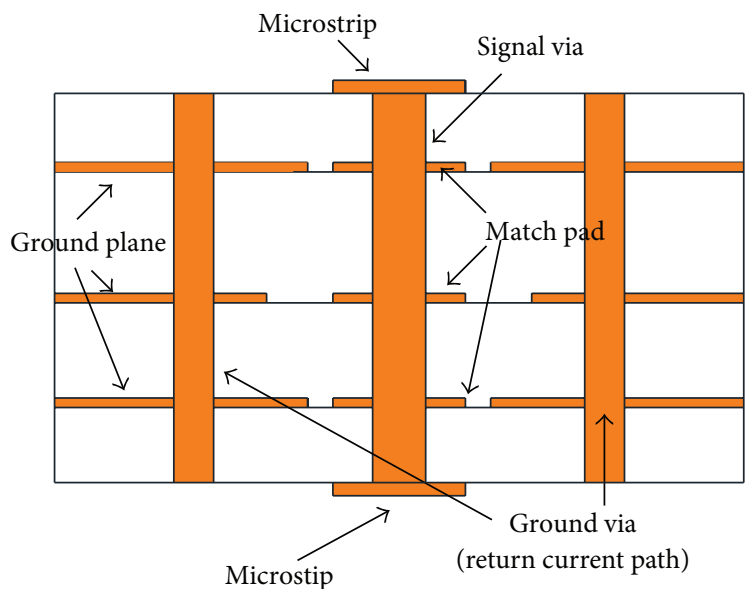

Figure 5: The cut front view of a via transition.

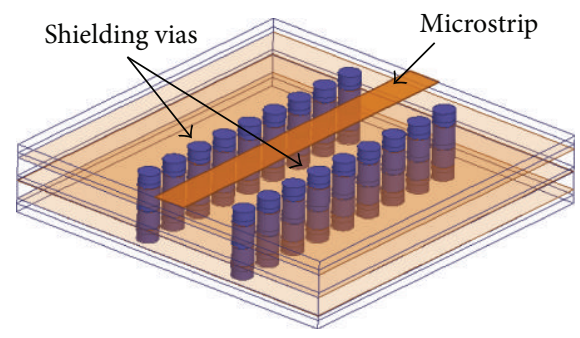

Figure 6: simi-CBCPW structure.

the signal-transmitting path; thus the return current path is curtailed relatively. When a balance is achieved between the signal path and the return current path, the transition of the signal in the multilayer circuit will reach a stage of perfection.

From Figure 7 we can get that the matching pads loaded transition design can keep the insertion loss changeless and get a return loss of approximately $-15 \mathrm{~dB}$ down values up to $11.6 \mathrm{GHz}$ at the same time. The transition design clearly expresses the excellent performance with the matching pads loaded signal via in the simulation.

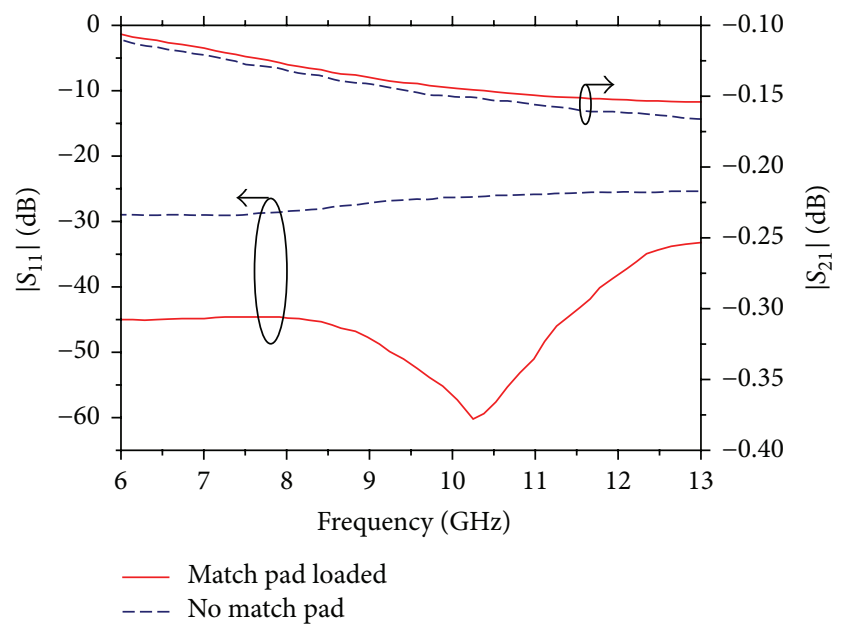

Figure 7: Function of the matching pads for signal transfer simulation.

The magic balance in order to attain the greater impedance matching was discovered by optimizing the radiuses of the matching pads and antipads in each ground plane. The feeding microstrip line, which has a width of $0.96 \mathrm{~mm}$ wide for the $0.374 \mathrm{~mm}$ composite substrate in the X-band, has been considered in the simulation result. Figure 4(a) shows the geometry of the top (or bottom) circuit surface with dimensions of $w=0.96 \mathrm{~mm}, D 1=0.5 \mathrm{~mm}, D v 1=$ $0.3 \mathrm{~mm}, D v 2=0.225 \mathrm{~mm}, H v 1=4.35 \mathrm{~mm}$, and $H v 2=$ $3.2 \mathrm{~mm}$. The diameters of the first ground plane planar graph in Figure 4(b) for the matching pads and antipad are $D \_m 1=$ $0.465 \mathrm{~mm}$ and $D \_a 1=0.84 \mathrm{~mm}$. Similarly, the parameters of the matching pads and antipad in the second and third ground layers are $D \_m 2=0.45 \mathrm{~mm}, D \_a 2=0.866 \mathrm{~mm}$, $D \_m 3=0.476 \mathrm{~mm}$, and $D \_a 3=0.866 \mathrm{~mm}$. As shown in Figure 7, the solid line shows the condition with the matching pads; the simulated $S$-parameters curves confirm that the return loss was above $44.5 \mathrm{~dB}$ up to $10.9 \mathrm{GHz}$ and the insertion loss was under $0.16 \mathrm{~dB}$ from $6 \mathrm{GHz}$ up to $13 \mathrm{GHz}$. 
TABLE 2: Parameters of matching pads loaded signals via transition investigation (unit: $\mathrm{mm}$ ).

\begin{tabular}{lrccc}
\hline Coax-like section & \multicolumn{5}{c}{$\begin{array}{c}\text { Match-pad and antipad } \\
\text { (all layers of ground plane) }\end{array}$} \\
\hline$H v 1 \quad H v 2$ & & & & \\
\hline $4.35 \quad 3.2$ & & $D \_a 1$ & $D \_a 2$ & $D \_a 3$ \\
\hline Through-hole via & $\begin{array}{r}D \_m \\
0.5\end{array}$ & 0.88 & 0.9 & 0.9 \\
\hline$D v 1 \quad D v 2$ & $\begin{array}{r}D \_m \\
0.6\end{array}$ & 1 & 1.1 & 1 \\
\hline $0.3 \quad 0.225$ & $\begin{array}{r}D \_m \\
0.7\end{array}$ & 1.2 & 1.2 & 1.2 \\
\hline
\end{tabular}

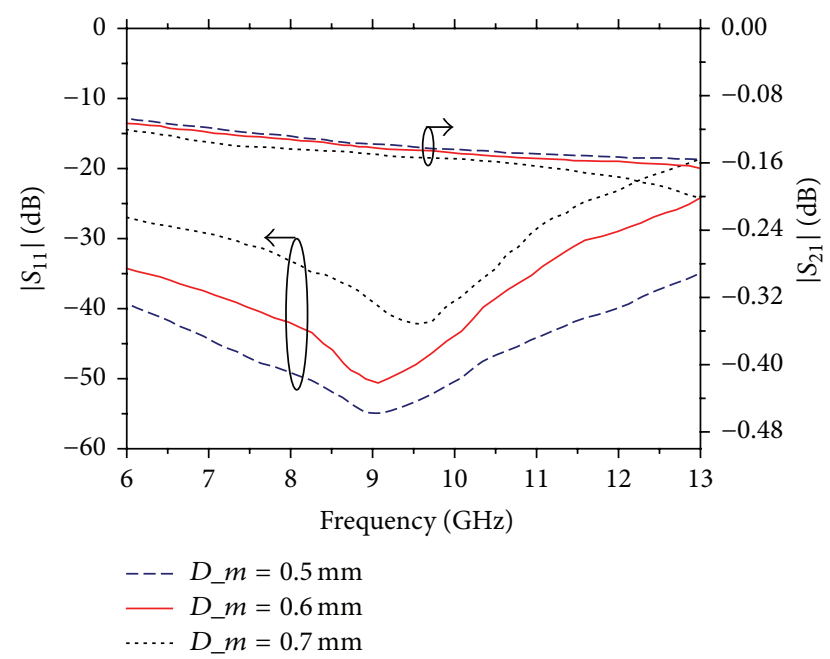

FIGURE 8: S-parameter of three cases for MS-to-MS transition.

Furthermore, the return loss achieved $60 \mathrm{~dB}$ at the $10 \mathrm{GHz}$ with the insertion loss $0.14 \mathrm{~dB}$.

In order to get more information from the idea of matching pads, three cases are given here. In the geometry, as shown in Figure 5, the diameter of each matching pad is settled while the diameters of antipads are variable, which could be implemented to find the best balance return current path through optimization. In Figure 8, the dashed line, solid line, and point line represent $D \_m=0.5 \mathrm{~mm}, D \_m=0.6 \mathrm{~mm}$, and $D m=0.7 \mathrm{~mm}$, respectively; the specific parameters are shown in Table 2. The lumped circuit model can be used to investigate the effects of via pad and antipad sizes on the $S$-parameter are shown in Figure 8, too. We can still get all impedances of each block calculated and simulated by the method of moments for different pad and antipad sizes. Then, the values of $L$ and $C$ of the equivalent circuit are extracted according to the impedance of each block. But due to the fact that the lumped circuit model is approximate equivalent circuit model, in order to get more accurate value, here we still use the electromagnetic field simulation software to design. In this setup, the return loss is above $40 \mathrm{~dB}$ within the 6$12 \mathrm{GHz}$ spectrum and the insertion loss is better than $0.16 \mathrm{~dB}$ up to $13 \mathrm{GHz}$ for the $D \_m=0.5 \mathrm{~mm}$ instance. The other two cases, by contrast, are the spectrum of $D \_m=0.6 \mathrm{~mm}$ case

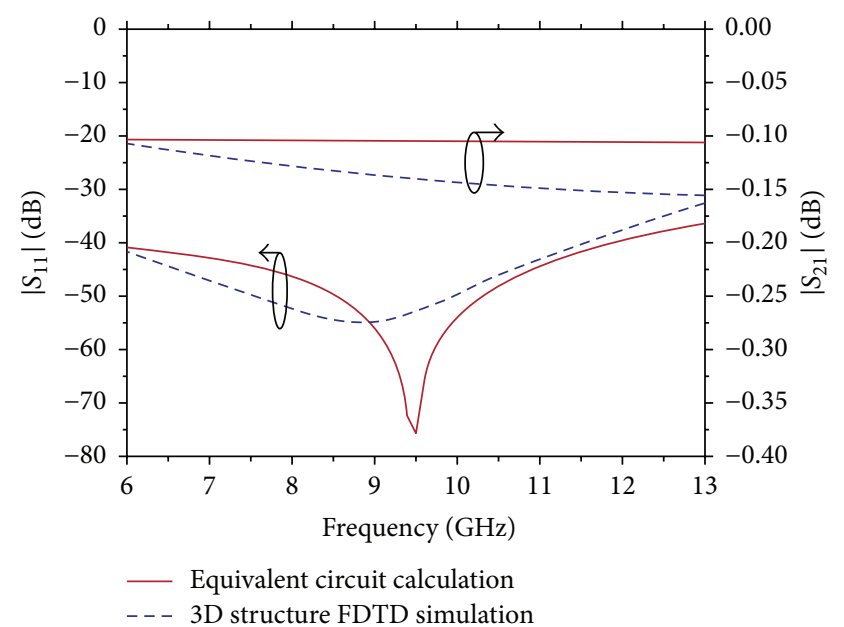

FIgURE 9: Contrast between the equivalent circuit calculation and 3D structure FDTD simulation.

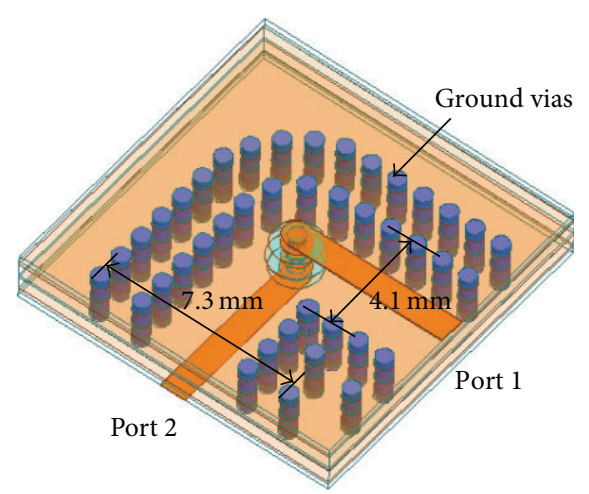

FIgURE 10: 3D view of the right angle MS-to-MS transition.

in which the return loss is above $40 \mathrm{~dB}$ only from $8 \mathrm{GHz}$ to $10 \mathrm{GHz}$ and also from $9.2 \mathrm{GHz}$ to $9.8 \mathrm{GHz}$ under the condition $D\lrcorner=0.7 \mathrm{~mm}$. The insertion loss is below $0.2 \mathrm{~dB}$ at $13 \mathrm{GHz}$ in all three cases. It is clear that by adopting the state of $D \_m=$ $0.5 \mathrm{~mm}$, the matching pads loaded structure will demonstrate better performance in signal transition, and all parameters will be favorable for the manufacturing tolerance.

The relevant results in Figure 9 indicate the match between the physics-based circuit calculation and the $3 \mathrm{D}$ structure simulation with the $D \_m=0.5 \mathrm{~mm}$ situation. Contrasting with the FDTD result, the two curves are in good agreement despite the $2 \mathrm{D}$ calculation being idealized because of the simplification of the physical significance linked circuit, verifying the validation of the physics-based equivalent circuit's conception.

Similar in structure to the microstrip-to-microstrip transition in Figure 2, three matching pads were loaded on the signal via in the right angle MS-to-MS transition, as shown in Figure 10. The microstrip on the bottom layer was turned at a right angle, the same as the shielding vias. The geometry with $D \_m=0.5 \mathrm{~mm}, D \_a 1=0.86 \mathrm{~mm}, D \_a 2=0.95 \mathrm{~mm}$, and $D \_a 3=0.88 \mathrm{~mm}$ was simulated using the coax-like vias adjacent to the signal via and the shielding vias near the sides 


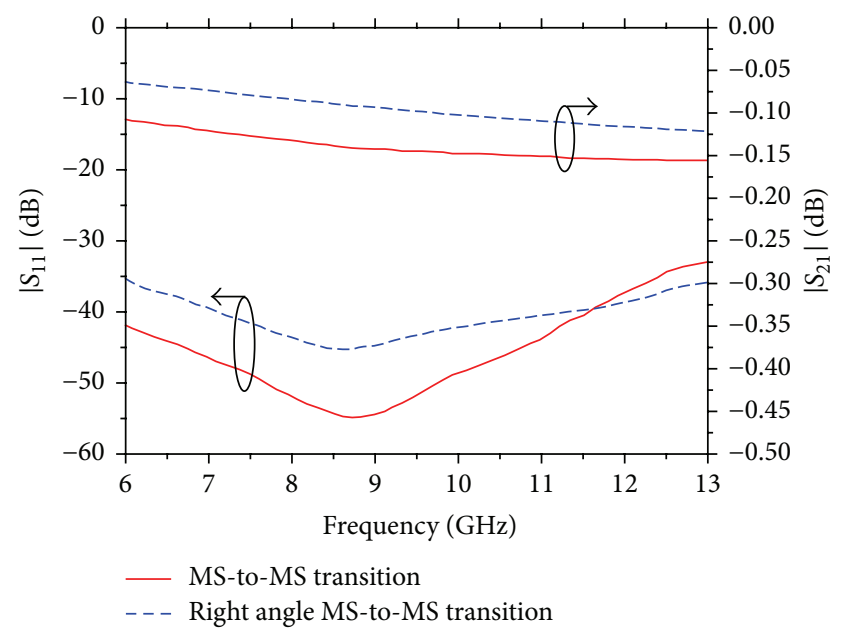

FIGURE 11: $S$-parameter of the right angle transition.

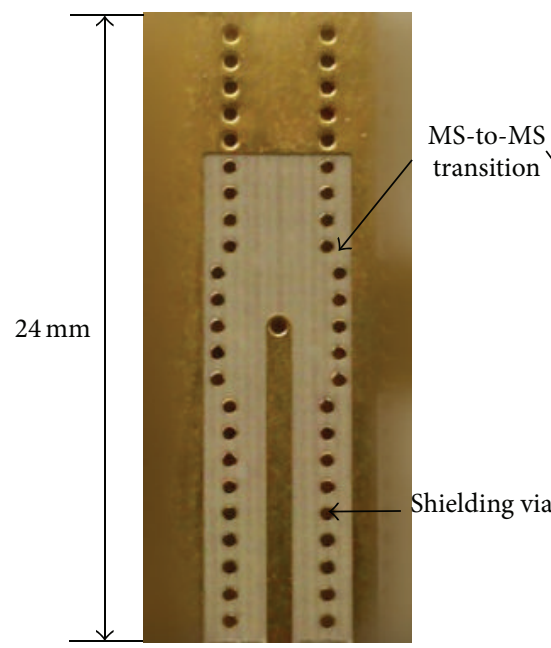

(a)

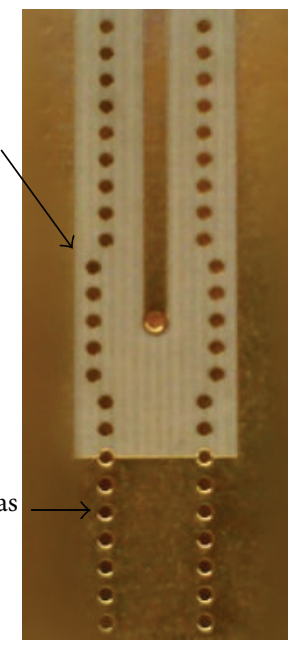

(b)
FIgURE 12: Fabricated circuit of the MS-to-MS transition. (a) Top view; (b) bottom view.

of the microstrip. Also, by using a similar method to contrast with the results of the microstrip-to-microstrip transition, the frequency range with a return loss above $40 \mathrm{~dB}$ was reduced to 7.3-11.4 GHz, while the insertion loss was better than the MS-to-MS transition result, approximately $0.4 \mathrm{~dB}$ in the full frequency range, as shown in Figure 11.

\section{Experimental Results and Discussion}

Figure 12 shows the photograph of the fabricated MS-to-MS transition with the matching pads loaded structure on the multilayer substrate. The parameters of the $D \_m=0.5 \mathrm{~mm}$ case were adopted to construct the entire transition structure. They were measured using an Agilent Vector Network Analyzer (E8363B). The $S$-parameters of this transition with the matching pads and the transition without the matching pads have been plotted in Figure 13. From $8 \mathrm{GHz}$ to $12 \mathrm{GHz}$,

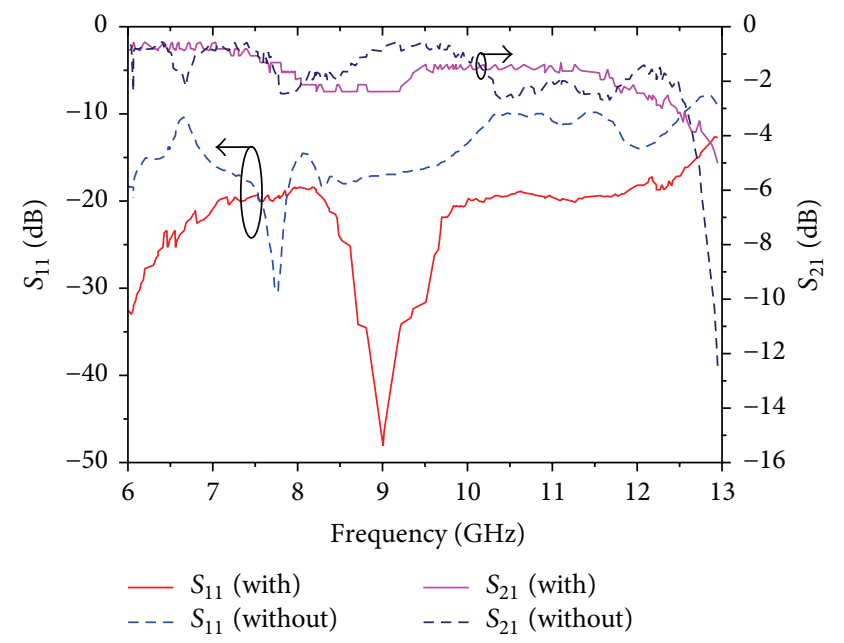

FIGURE 13: The measured S-parameter of MS-to-MS transition with and without the matching pads.

the insertion loss of the two kinds of the transition is not very different, but the return loss of the transition with the matching pads is much better than that without the matching pads, as shown in Figure 13. In the frequency band range from $8.35 \mathrm{GHz}$ to $10.2 \mathrm{GHz}$, not including the insertion loss of two SMA connectors, the return loss is better than $20 \mathrm{~dB}$ and the insertion loss is below $0.8 \mathrm{~dB}$. The return loss achieved $-48.2 \mathrm{~dB}$ at $9 \mathrm{GHz}$, close to the center frequency of the wanted band. For a wider band, the return loss is above $19 \mathrm{~dB}$ and insertion loss is under $1.16 \mathrm{~dB}$ from $8 \mathrm{GHz}$ to $12 \mathrm{GHz}$.

It seems that the experimental results did not correspond well to the simulation result. To further aid in the investigation of this problem, a 3D model was raised to imitate the true nature of measurement. In Figure 14(a), only a microstrip line with shielding vias (simi-CBCPW structure) mounted on a multilayer substrate, and two SMA connectors have been placed at the beginning and end of the microstrip. Considering the actual situation, a $0.1 \mathrm{~mm}$ air gap between the SMA connector (metal wall of the chamber) and the microstrip cannot be ignored. This gap will cause signal coupling to the other layers between the ground plane pairs and signal radiation as shown in Figure 14(b), which plots the electric field in the whole space. No remedial measures used to destroy the electromagnetic field in the air gap will successfully avoid the reduction of transition performance.

\section{Conclusion}

In this paper, a matching pads loaded X-band microstripto-microstrip via transition was presented and studied. The use of the match-pad design was powerful in improving the impedance matching level, achieving a lower return loss and, therefore, enhancing the package performance. In addition, coax-like vias and shielding vias were also employed to serve as the return current path and to reduce the EMI level. Each lumped impedance of the system was carefully calculated in the physics-based equivalent circuit. Simulation results showed that the return loss was above $40 \mathrm{~dB}$ within 


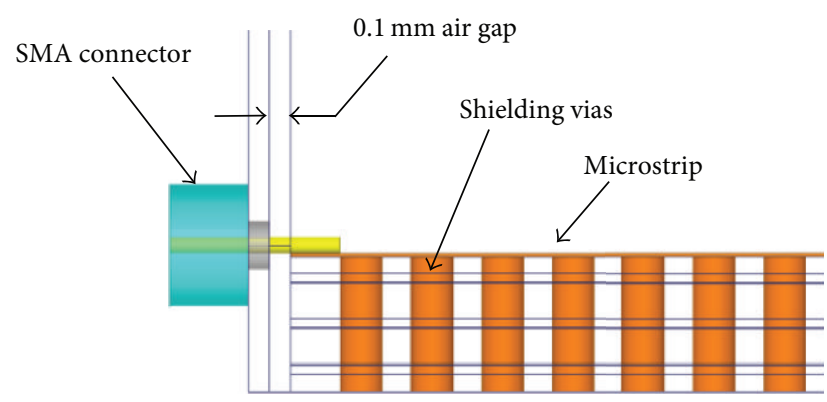

(a)

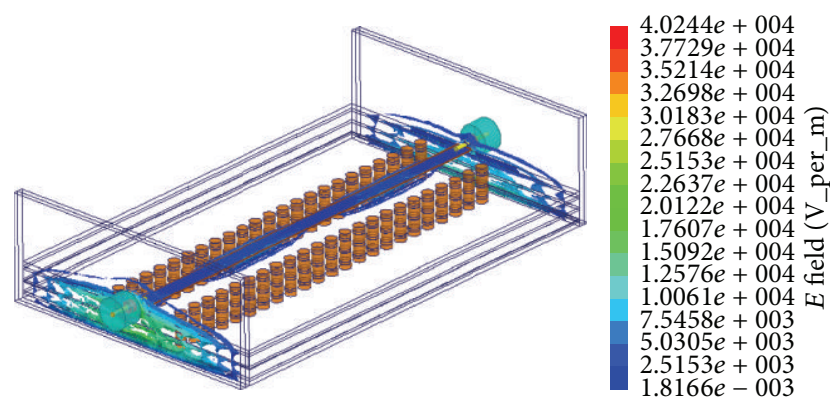

(b)

Figure 14: A 3D model for imitating the true nature of measurement. (a) Side view of the 3D structure; (b) diagram of the simulated electric field.

the 6-12 GHz spectrum and the insertion loss was better than $0.16 \mathrm{~dB}$ up to $13 \mathrm{GHz}$. In the test link, the impact of $0.1 \mathrm{~mm}$ air gap between the metal wall and the multilayered substrate was considered and analyzed. There is no doubt that the air gap, which is offset, will also cause the degradation in signal transmission at high frequencies.

\section{Competing Interests}

The author declares that he has no competing interests.

\section{References}

[1] T. Kangasvieri, M. Komulainen, H. Jantunen, and J. Vähäkangas, "High performance vertical interconnections for millimeter-wave multichip modules," in Proceedings of the 35th European Microwave Conference, vol. 1, pp. 169-172, Paris, France, October 2005

[2] R. Sturdivant, C. Ly, J. Benson, and M. Hauhe, "Design and performance of a high density 3D microwave module," in Proceedings of the 1997 IEEE MTT-S International Microwave Symposium, vol. 2, pp. 501-504, June 1997.

[3] W. Shi, Z. Qian, J. Zhou, X. Qu, Y. Xiang, and L. Hong, "A small ku-band polarization tracking active phased array for mobile satellite communications," International Journal of Antennas and Propagation, vol. 2013, Article ID 747629, 12 pages, 2013.

[4] Y. He, F. Liu, F. Hou et al., "Design and implementation of a 7002,600 MHz RF SiP module for micro base station," Microsystem Technologies, vol. 20, no. 12, pp. 2295-2300, 2014.

[5] M. F. Shafique and I. D. Robertson, "Laser prototyping of multilayer LTCC microwave components for system-in-package applications," IET Microwaves, Antennas and Propagation, vol. 5, no. 8, pp. 864-869, 2011.

[6] A. Bessemoulin, M. Parisot, P. Quentin, C. Saboureau, M. Van Heijningen, and J. Priday, "A 1-watt Ku-band power amplifier MMIC using cost-effective organic SMD package," in Proceedings of the 34th European Microwave Conference, vol. 1, pp. 349352, October 2004.

[7] S.-K. Yeo, J.-H. Chun, and Y.-S. Kwon, "A 3-D X-band T/R module package with an anodized aluminum multilayer substrate for phased array radar applications," IEEE Transactions on Advanced Packaging, vol. 33, no. 4, pp. 883-891, 2010.

[8] F. Alimenti, P. Mezzanotte, G. Tasselli, A. Battistini, V. Palazzari, and L. Roselli, "Development of low-cost 24-GHz circuits exploiting system-in-package ( $\mathrm{SiP})$ approach and commercial PCB technology," IEEE Transactions on Components, Packaging and Manufacturing Technology, vol. 2, no. 8, pp. 1265-1274, 2012.

[9] S. Pan and J. Fan, "Characterization of via structures in multilayer printed circuit boards with an equivalent transmissionline model," IEEE Transactions on Electromagnetic Compatibility, vol. 54, no. 5, pp. 1077-1086, 2012.

[10] A. R. Diewald and R. H. Jansen, "Analysis of vertical via current increase due to via cylinder-to-ground capacitance," in Proceedings of the IEEE 7th European Microwave Integrated Circuits Conference (EuMIC '12), pp. 151-154, Amsterdam, The Netherlands, October 2012.

[11] C.-C. Tsai, Y.-S. Cheng, T.-Y. Huang, Y. A. Hsu, and R.-B. Wu, "Design of microstrip-to-microstrip via transition in multilayered LTCC for frequencies up to $67 \mathrm{GHz}$," IEEE Transactions on Components, Packaging and Manufacturing Technology, vol. 1, no. 4, pp. 595-601, 2011.

[12] A. R. Diewald and R. H. Jansen, "Analysis of vertical via current increase due to via cylinder-to-ground capacitance," in Proceedings of the 7th European Microwave Integrated Circuits Conference (EuMIC '12), pp. 151-154, Amsterdam, The Netherlands, October 2012.

[13] S. Wu, X. Chang, C. Schuster, X. Gu, and J. Fan, "Eliminating via-plane coupling using ground vias for high-speed signal transitions," in Proceedings of the 17th Conference on Electrical Performance of Electronic Packaging (EPEP '08), pp. 247-250, San Jose, Calif, USA, October 2008.

[14] R. Rimolo-Donadio, G. Selli, F. De Paulis et al., "Signal integrity: efficient, physics-based via modeling: integration of striplines," IEEE Electromagnetic Compatibility Magazine, vol. 1, no. 2, pp. 74-81, 2012.

[15] J. Fan, A. Hardock, R. Rimolo-Donadio et al., "Signal integrity: efficient, physics-based via modeling: return path, impedance, and stub effect control," IEEE Electromagnetic Compatibility Magazine, vol. 3, no. 1, pp. 76-84, 2014.

[16] C.-C. Tsai and Y.-S. Cheng, "Design of microstrip-to-microstrip via transition in multilayered LTCC for frequencies up to $67 \mathrm{GHz}$," IEEE Transactions on Components, Packaging and Manufacturing Technology, vol. 1, no. 4, pp. 595-601, 2011.

[17] E. R. Pillai, "Coax via-a technique to reduce crosstalk and enhance impedance match at vias in high-frequency multilayer packages verified by FDTD and MoM modeling," IEEE Transactions on Microwave Theory and Techniques, vol. 45, no. 10, pp. 1981-1985, 1997. 
[18] S. Pan and J. Fan, "Characterization of via structures in multilayer printed circuit boards with an equivalent transmissionline model," IEEE Transactions on Electromagnetic Compatibility, vol. 54, no. 5, pp. 1077-1086, 2012.

[19] E. Laermans, J. De Geest, D. De Zutter, F. Olyslager, S. Sercu, and D. Morlion, "Modeling differential via holes," IEEE Transactions on Advanced Packaging, vol. 24, no. 3, pp. 357-363, 2001.

[20] C.-J. Ong, B. Wu, L. Tsang, and X. Gu, "Full-wave solver for microstrip trace and through-hole via in layered media," IEEE Transactions on Advanced Packaging, vol. 31, no. 2, pp. 292-302, 2008.

[21] J. Kim, K. Shringarpure, J. Fan, J. Kim, and J. L. Drewniak, "Equivalent circuit model for power bus design in multilayer PCBs with via arrays," IEEE Microwave and Wireless Components Letters, vol. 21, no. 2, pp. 62-64, 2011. 


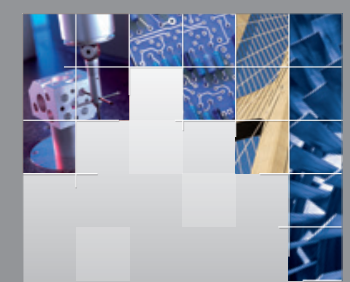

\section{Enfincering}
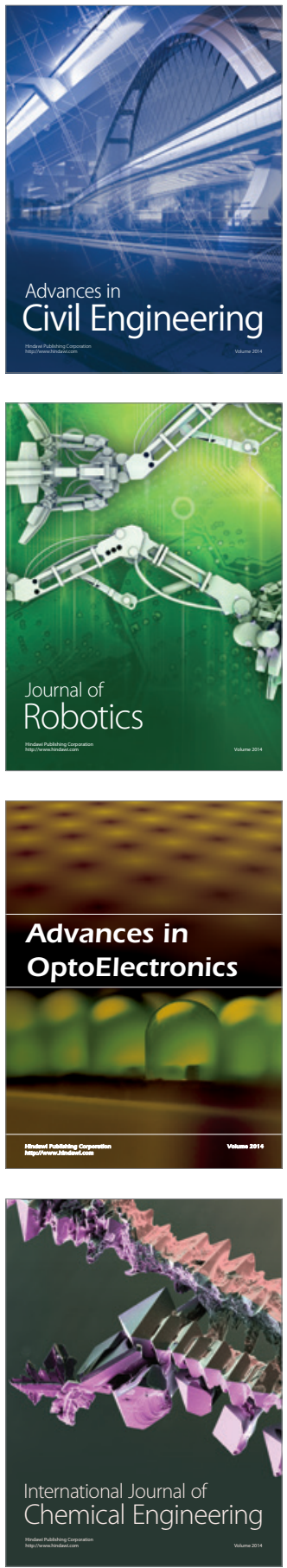

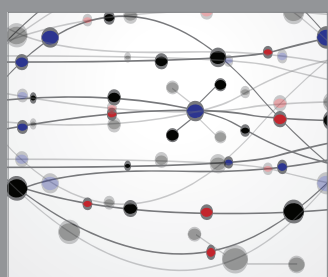

The Scientific World Journal

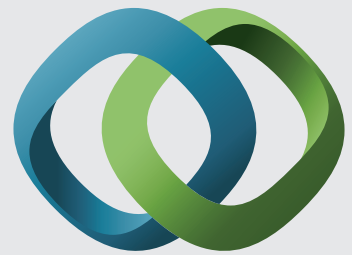

\section{Hindawi}

Submit your manuscripts at

http://www.hindawi.com
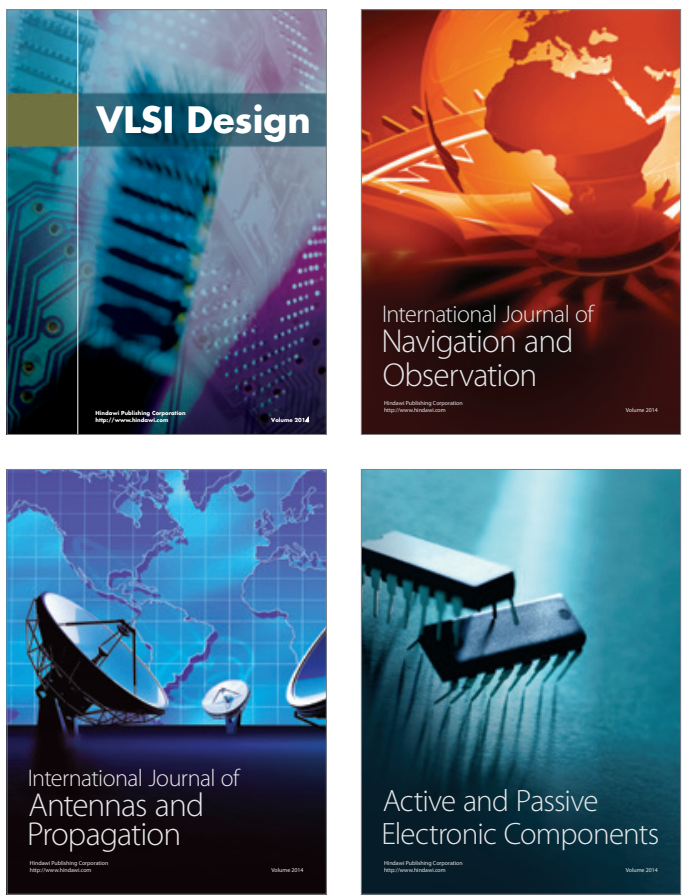
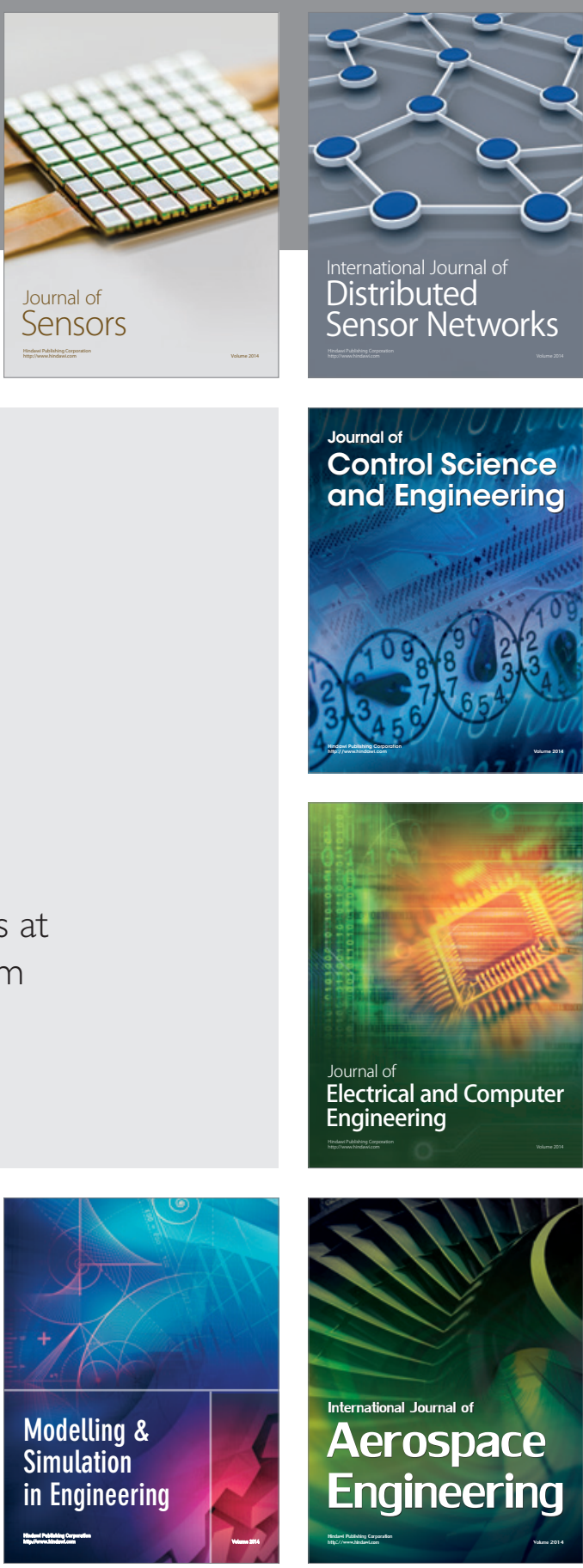

International Journal of

Distributed

Sensor Networks

Journal of

Control Science

and Engineering
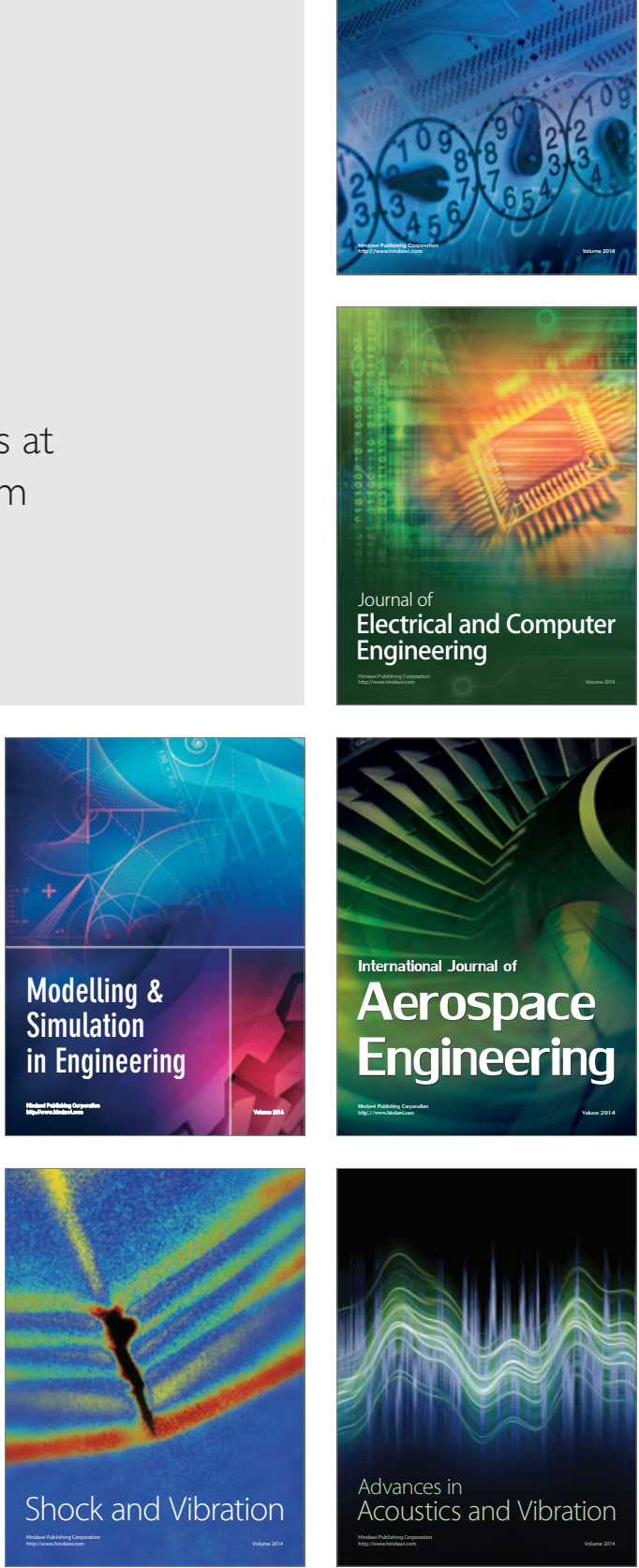